\title{
SPESIES GASTROPODA YANG TERDAPAT PADA KAWASAN TEREKSPLOITASI DI PADANG SERAI KAMPUNG MELAYU PULAU BAAI KOTA BENGKULU
}

\author{
Pika Lusi Andriati ${ }^{1}$, Syamsul Rizal $^{2}$ \\ ${ }^{1}$ Mahasiswa Program Studi Biologi, Fakultas Matematika dan Ilmu Pengetahuan Alam \\ Universitas PGRI Palembang \\ ${ }^{2}$ Dosen Program Studi Biologi, Fakultas Matematika dan Ilmu Pengetahuan Alam \\ Universitas PGRI Palembang \\ *e-mail: Pikalusiandriati27@gmail.com
}

\begin{abstract}
ABSTRACK
Research on gastropod species found in exploited tourism areas in Padang Serai, the Malay village of Baai island, Bengkulu city, was carried out in March - June 2020 aimed to find out what gastropod species found in the exploited tourist area in Padang Serai, the Malay village, Baai island, Bengkulu city, Bengkulu. The study used a purposive sampling method, where sampling was conducted by exploring methods by determining 3 observation stations, station 1 with rocky and muddy substrates, station 2 muddy and sandy, and station 3 with rocky, muddy, and sandy substrates. Data collected by making observations or direct observation of the species being observed. The results showed that Gastropods found consisted of 9 orders, 14 families, 15 genera, and 16 species namely Patelloida striata, Cellana rota, Trochus henleyanus, Trochus maculatus, Umbonium costatum, Nerita picea, Tectarius coronatus, Cypraea annulus, Conus quercinus, Natica, Natica stellate, Bursa bufonia, Murex trapa, Nassarius arcularius, Hastula hectica, Achatina fulica, and Architectonica maxima. Station 1, the presence of gastropods is threatened while station 2, the presence of gastropods is quite good, and station 3, the presence of gastropods, there are still many species found in that location.
\end{abstract}

Keywords: Gastropoda, Purposive Sampling Method, Observation and Padang Lemongrass

\begin{abstract}
ABSTRAK
Penelitian tentang spesies gastropoda yang terdapat pada kawasan wisata tereksploitasi di Padang Serai kampung Melayu pulau Baai kota Bengkulu telah dilaksanakan pada bulan Maret - Juni 2020 bertujuan untuk mengetahui spesies gastropoda apa saja yang terdapat pada kawasan wisata tereksploitasi di Padang Serai kampung Melayu pulau Baai kota Bengkulu. Penelitian menggunakan metode purposive sampling, dimana pengambilan sampel dilakukan dengan metode menjelajah dengan menentukan 3 stasiun pengamatan, stasiun 1 bersubstrat berbatu dan berlumpur, stasiun 2 berlumpur dan berpasir, dan stasiun 3 bersubstrat berbatu ,berlumpur, dan berpasir.Data dikumpulkan dengan melakukan observasi atau pengamatan langsung terhadap spesies yang diamati. Hasil penelitian menunjukkan bahwa Gastropoda yang ditemukan terdiri dari 9 Ordo, 14 familia, 15 Genus, dan 16 Spesies yaitu Patelloida striata, Cellana rota, Trochus henleyanus, Trochus maculatus, Umbonium costatum, Nerita picea, Tectarius coronatus, Cypraea annulus, Conus quercinus, Natica stellate, Bursa bufonia, Murex trapa, Nassarius arcularius, Hastula hectica, Achatina fulica, dan Architectonica maxima.Stasiun 1 keberadaan gastropoda mulai terancam sedangkan stasiun 2 keberadaan gastropoda cukup baik dan stasiun 3 keberadaan gastropoda baik masih banyak spesies yang ditemukan di lokasi tersebut.
\end{abstract}

Kata Kunci: Gastropoda, Metode Purposive Sampling, Observasi dan Padang Serai 


\section{PENDAHULUAN}

Kawasan wisata adalah suatu kawasan yang mempunyai luas tertentu yang sengaja dibangun dan disediakan untuk kegiatan pariwisata atau jasa wisata. Jika dikaitkan dengan pariwisata air, pengertian tersebut berarti suatu kawasan yang disediakan untuk kegiatan pariwisata dengan daya tarik kawasan perairan. Kawasan wisata merupakan wilayah terluas di dunia yang memiliki keanekaragaman yang sangat tinggi dan strukturnya yang bervariasi.

Ekosistem perairan sangat penting dikarenakan banyak hewan dan tumbuhan yang hidupnya untuk tinggal di ekosistem ini (Schaduw, 2015). Salah satu biota yang sering ditemui di ekosistem perairan adalah moluska. Moluska yang paling banyak dijumpai di kawasan wisata yaitu gastropoda (Saptrini et al., 2011).

Gastropoda memiliki peranan yang sangat penting baik dari segi ekonomi dan ekologi, dari segi ekonomi gastropoda memiliki harga jual yang tinggi sedangkan dari segi ekologi gastropoda berperan sebagai konsumen. Sifat dari gastropoda yang selalu menetap yang mengakibatkan spesies ini menerima setiap perubahan yang terjadi di kawasan wisata yang secara langsung dapat mempengaruhi kelimpahan gastropoda (Hartoni dan Agusalim, 2013).

Gastropoda yaitu kelompok hewan invertebrata bertubuh lunak yang berjalan dengan kaki perut dan secara umum memiliki cangkang. Hewan ini umum dikenal dengan keong atau siput. Secara ekologis gastropoda mempunyai peranan penting didalam rantai makanan di ekosistem air tawar, karena umumnya gastropoda bersifat herbivora, karnivora detritivor, deposit feeder, suspension feeder, dan parasit, sebagaian besar adalah pemakan detritud dan serasah dari daun yang jatuh dan mensirkulasi zat-zat yang tersuspensi di dalam air berguna untuk mendapatkan makanan, lumut dan aneka ganggang. Beberapa jenis gastropoda biasa dikonsumsi oleh manusia sebagai makanan membantu dalam proses rantai makanan dan siklus nutrient yang melibatkan kawasan wisata, gastropoda dijadikan konsumen pertama maupun sebagai pengurai.

Cangkang yang ada pada gastropoda tersusun dari bahan kalsium karbonat yang turut serta dalam siklus karbon yang terjadi di perairan walaupun perlu dikaji lebih lanjut (Isnaningsih dan Patria, 2018). Gastropoda merupakan kelas terbesar dari filum Moluska. Gastropoda memiliki penyebaran yang sangat luas luas, mulai dari wilayah pasang surut sampai kedalaman 8200 M (Siwi et al., 2017).

Pulau Baai adalah pulau di bagian barat Pulau Sumatra, tepatnya Provinsi Bengkulu. Jaraknya sekitar $20 \mathrm{~km}$ dari ibu kota Bengkulu. Tempat ini adalah pelabuhan perikanan dan perkampungan yang sedang ditingkatkan kapasitasnya menjadi pelabuhan internasional. Pulau Baai Bengkulu merupakan satu-satunya pelabuhan utama di Provinsi Bengkulu yang berhadapan langsung dengan Samudra Hindia yang letaknya dikecamatan Selebar kota Bengkulu berada pada posisi 03 47'30''LS dan 102 15'04''BT (Supiyati et al.,2012).

Pelabuhan Pulau Baai adalah pelabuhan semi alamya itu suatu pelabuhan yang terlindung oleh lidah pantai yang terjadi secara alami dan dilakukan pemotongan lidah pantai dengan cara mengeruk hingga ke dalam 10 meter untuk akses kapal masuk ke dalam pelabuhan. Sepanjang lidah pantai ditumbuhi ekosistem pohon kelapa dan pohon cemara akan tetapi diberbagai titik terjadi perusakan atau penebangan pohon untuk keperluan pembangunan jalan karena di lidah pantai dihuni oleh warga setempat maupun pendatang (Indasari, 2014).

Berdasarkan permasalahan yang ada di lingkungan kawasan wisata melihat pentingnya peranan gastropoda pada 
ekosistem perairaan maka telah dilakukan penelitian dengan tujuan untul mengetahui Spesies Gastropoda apa saja yang terdapat pada Kawasan Wisata Tereksploitasi di Padang Serai kampung Melayu pulau Baai kota Bengkulu.

\section{BAHAN DAN METODE}

Penelitian telah dilaksanakan pada bulan Maret sampai Juni 2020 di Padang Serai kampung Melayu pulau Baai kota Bengkulu. Identifikasi Gastropoda dilakukan di Laboratorium Biologi Fakultas MIPA Universitas PGRI Palembang. Alat dan bahan yang digunakan saringan, mistar, botol sampel, lup, pisau, sekop semen, penyungkit, ember, parang, thermometer, baki plastik, kantong plastik, alat tulis, dan label. Sedangkan bahan yang digunakan ialah alkohol $70 \%$. Metode penelitian menggunakan penelitian deskriptif dengan penentuan lokasi dilakukan berdasarkan teknik Purposive Sampling dengan mempertimbangkan lokasi dan situasi yang diperhitungkan. Penentuan titik lokasi berdasarkan titik koordinat dapat dilihat pada gambar dibawah ini.

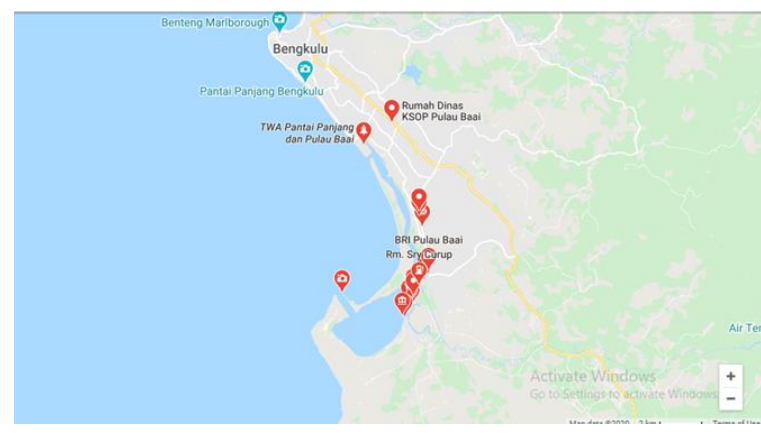

Gambar 1. Peta Lokasi Penelitiaan Sumber : Google Maps 2020

Penjelajahan dibagi menjadi 3 stasiun dan setiap stasiun dibagi menjadi 3 bagian berdasarkan tipe substrat. Stasiun I terdiri atas tipe substrat berbatu dan berlumpur yang terletak di dipermukiman padat penduduk, banyak penebangan pohon untuk dijadikan pondok-pondok wisatawan dan terdapat pohon kelapa dilihat dari ekologinya biasanya gastropoda dari family Conidae dan Terebridae (Ira et al., 2015).

Stasiun II terdiri atas tipe substrat berlumpur dan berpasir yang terletak di permukiman tidak terlalu padat, di stasiun II terdapat pohon kelapa, pohon cemara, pohon waru, dan rumput-rumput liar dilihat dari ekologinya biasanya gastropoda dari family Muricidae (Rangan, 2010). Stasiun III terdiri atas tipe substrat berbatu, berlumpur, dan berpasir yang terletak di tepian kawasan wisata hingga perbatasan pulau Baai, kawasan di stasiun III terdapat pohon-pohon besar yang rimbun, pohon cemara yang mengelilingi kawasan ini, adapun batu-batu besar. Tempat ini sangat cocok dijadikan liburan dikarenakan kawasan ini masih alami dan pemandangan alam yang menarik, habitat yang termasuk dalam substrat ini berfamily Ellobiidae, Planaxidae, Littorinidae, Melampidae, Mitridae, Naticidae, Neritidae, Potaminididae, Bursidae, Trochidae dan Synceriida (Nurmiati et al., 2016).

Metode menjelajah ini dimodifikasi menurut Shalihah (2017) menggunakan metode hand sorting pengambilan sampel dengan menggunakan tangan yang berada disetiap alur yang ditentukan setiap sampel yang diambil bisa berupa sampel yang masih hidup dan mati, dalam metode ini juga menggunakan alat bantu seperti pisau, penyungkit, parang dan sekop untuk mengambil gastropoda yang hidup didalam substrat, sampel dimasukan kedalam kantong yang telah di beri alkohol untuk megawetkan sampel selanjutnya dibawa ke laboratorium untuk mengidentifikasi sampel. Agar memudahkan dalam penelitian dilaksanakan ketika permukaan air surut, dan sore hari hingga petang biasanya gastropoda keluar untuk mencari makan. Dalam Penelitian ini juga dibantu oleh masyarakat 
lokal yang tahu akan keberadaan gastropoda pada ekosistem perairan di kota Bengkulu.

Setelah sampel di kumpulkan dan dibawa ke laboratorium, sampel di letakan ke baki plastik lalu amati dan analisis morfologi gastropoda dengan bantuan buku identifikasi " Fao Spesies Identification Guide For Fishery Purposes.The Living Marine Resources Of The Western Central Pacific. Volume $\quad 1 . \quad$ Seaweeds, Corals,Bivalves and Gastropods, 1998."

\section{HASIL DAN PEMBAHASAN}

Stasiun 1 yang terdiri dari 3 ordo (Trochida, Neogastropoda, dan Heterobranchia), 4 familia (Trochidae, Nassaridae, Terebridae, dan Pleurodinitidae) dan 4 spesies (Umbonium costatum, Nassarius arcularis, Hastula hectica, dan Achatina fulica) dengan substrat berbatu dan berlumpur biasanya yang sering ditemukan ialah familia Conidae dan Terebridae, gastropoda ini memiliki cangkang kerang yang sangat tinggi dengan banyak uliran dan kanal anterior pendek (Ira et al., 2015).

Stasiun 2 yang terdiri 5 ordo (Archeogastropoda, Trochida, Littorinimorpha, Caenogastropoda, dan Neogastropoda), 6 familia (Trochidae, Littorinidae, Bursidae, Muricidae, Nassaridae, dan Terebridae) dan 8 spesies (Trochus henleyanus, Trochus maculatus, Umbonium costatum, Tectarius coronatus, Bursa bufonia, Murex trapa, Nassarius arcularis, dan Hastula hectica) dengan substrat berpasir dan berbatu biasanya spesies yang sering dijumpai ialah familia Muricidae meliki cangkang unik umunya dengan rusuk dan operculumnya tebal (Rangan, 2010).

Stasiun 3 yang terdiri 9 ordo (Patellogastropoda, Archeogastropoda, Trochida, Neritimorpha, Littorinimorpha, Mesogastropoda, Caenogastropoda, Neogastropoda, dan Heterobranchia), 12 familia (Lottidae,Trochidae, Neritidae, Littorinidae, Cypraeidae, Naticidae, Bursidae, Muricidae, Conidae, Architectonicidae, Patellidae)dan 13 spesies (Patelloida striata, Trochus henleyanus, Trochus maculatus, Umbonium costatum, Nerita picea, Tectarius coronatus, Cyprea annulus, Natica stellate, Bursa bufonia, Murex trapa, Conus quercinus, Architectonica maxima dan Cellana erosa) dengan substrat berbatu, berpasir dan berlumpur gastropoda mudah berkembangbiak karena gastropoda sangat menyukai habitat yang lembab. Substrat seperti ini biasanya familia Ellobiidae, Plaxidae, Littorinidae, Melampidae, Mitridae, Naticidae, Nerotidae, Potaminidae, Bursidae, Trochidae, Dan Synceriida, gastropoda ini memiliki cangkang yang menyerupai mainan berputar atas (Nurmiati et al., 2016).

Gastropoda di Padang Serai Kampung Melayu Pulau Baai Kota Bengkulu, memiliki tingkat keberadaan gastropoda yang relative baik, karena keberadaan gastropoda yang rendah hanya dikawasan yang telah tercemar dan tercampur tangan manusia. Gastropoda yang sulit ditemui yaitu di stasiun 1, sebab lokasi ini berdekatan dengan permukiman warga yang beraktifitas sebagai nelayan dan banyak sekali kapal-kapal warga yang tersandar di pinggiran kawasan wisata mengakibatkan gastropoda yang berhabitat di stasiun 1 rendah keberadaannya.

Stasiun 1 memiliki substrat berbatu dan berlumpur kawasan ini tidak tergenang air dengan ekosistem perairan yang termasuk komunitas bahari dangkal yang sangat menarik, berada di perairan tropik dan subtropik, di daerah yang berbeda dalam jangkauan pasang surut seperti di muara sungai atau sungai pasang berlumpur. Sedangkan di pantai berpasir atau berbatu ataupun karang berpasir tumbuhnya tidak akan baik. Begitu pula 
arus yang kuat misalnya karena seringnya dilewati manusia dengan kapal motor akan dapat menghancurkan hutan lindung (Ahmad, 2018).

Gastropoda di stasiun 3 banyak ditemukan gastropoda dikarenakan kawasan ini masih alami, jauh dari permukiman penduduk dan tempat industri maka dikawasan ini banyak ditemui gastropoda yang berkembangbiak.

Habitat di stasiun 3 masih baik, menurut Turra dan Denadai (2006) dalam Triwiyanto et al., (2015) yang mengatakan bahwa "Gastropoda adalah salah satu moluska yang banyak dijumpai di berbagai substrat, hal ini disebabkan oleh gastropoda yang memiliki kemampuan adaptasi yang lebih tinggi dibandingkan dengan kelas yang lain baik di substrat yang keras maupun lunak".

Menurut Syafikri (2008) dalam Andrianna (2016) mengatakan bahwa sebagian dari gastropoda juga hidup di daerah perairan, ada yang hidupnya di lumpur atau tanah yang tergenang air, ada juga yang menempel pada akar dan batangnya, bahkan adapula yang memiliki kemampuan memanjat.

Gastropoda hewan yang dapat dijumpai diberbagai lingkungan sehingga dapat menyesuaikan diri tergantung tempat hidupnya. Hasil Pengamatan Gastropoda yang terdapat pada kawasan Wisata tereksploitasi di Padang Serai Kampung Melayu Pulau Baai Kota Bengkulu, disajikan dalam Tabel 1 berikut: 
Tabel 1. Hasil Pengamatan Gastropoda yang terdapat pada kawasan Wisata tereksploitasi di Padang Serai Kampung Melayu Pulau Baai Kota Bengkulu

\begin{tabular}{|c|c|c|c|c|c|c|c|}
\hline \multirow[t]{2}{*}{ No. } & \multirow[t]{2}{*}{ Ordo } & \multirow[t]{2}{*}{ Familia } & \multirow[t]{2}{*}{ Genus } & \multirow[t]{2}{*}{ Spesies } & \multicolumn{3}{|c|}{$\begin{array}{l}\text { Tempat ditemukan } \\
\text { Stasiun ke- }\end{array}$} \\
\hline & & & & & $\mathbf{I}$ & II & III \\
\hline 1. & Patellogastropoda & Lottidae & Patelloida & Patelloida striata & & & $\sqrt{ }$ \\
\hline 2. & & Patellidae & Cellana & Cellana erosa & & & $\sqrt{ }$ \\
\hline 3. & Archaeogastropoda & Trochidae & Trochus & Trochus henleyanus & & $\sqrt{ }$ & $\sqrt{ }$ \\
\hline 4. & & & & Trochus maculatus & & $\sqrt{ }$ & $\sqrt{ }$ \\
\hline 5. & Trochida & & Umbonium & Umbonium costatum & $\sqrt{ }$ & $\sqrt{ }$ & $\sqrt{ }$ \\
\hline 6. & Neritimorpha & Neritidae & Nerita & Nerita picea & & & $\sqrt{ }$ \\
\hline 7. & Littorinimorpha & Littorinidae & Tectarius & Tectarius coronatus & & $\sqrt{ }$ & $\sqrt{ }$ \\
\hline 8. & Mesogastropoda & Cypraeidae & Cypraea & Cypraea Annulus & & & $\sqrt{ }$ \\
\hline & & Conidae & Conus & Conus quercinus & & & $\sqrt{ }$ \\
\hline 9. & Caenogastropoda & Naticidae & Natica & Natica stellata & & & $\sqrt{ }$ \\
\hline 10. & & Bursidae & Bursa & Bursa bufonia & & $\sqrt{ }$ & $\sqrt{ }$ \\
\hline 11. & Neogastropoda & Muricidae & Murex & Murex trapa & & $\sqrt{ }$ & $\sqrt{ }$ \\
\hline 12. & & Nassaridae & Nassarius & Nassarius arcularius & $\sqrt{ }$ & $\sqrt{ }$ & \\
\hline 14. & & Terebridae & Hastula & Hastula hetica & $\sqrt{ }$ & $\sqrt{ }$ & \\
\hline 15. & Heterobranchia & Pleurodintidae & Achatina & Achatina fulica & $\sqrt{ }$ & & \\
\hline 16. & & Architectonicidae & Architectonica & Architectonica maxima & & & $\sqrt{ }$ \\
\hline
\end{tabular}




\section{KESIMPULAN}

Jenis-jenis gastropoda yang di peroleh dari kawasan wisata terdiri dari 16 spesies yaitu Patelloida striata, Trochus henleyanus, Trochus maculatus, Umbonium costatum, Nerita picea, Tectarius coronatus, Cypraea annulus, Natica stellata, Bursa bufonia, Murex trapa, Nassarius arcularis, Conus quercinus, Hastula hetica, Achatina fulica, Architectonica maxima, dan Cellana erosa. Gastropoda yang di dapat tergolong ke dalam 10 Ordo, 14 Familia, 16 Genus, dan 16 Spesies.

\section{DAFTAR PUSTAKA}

Ahmad, 2018.Identifikasi Filum Mollusca (Gastropoda) Di Perairan Palipi Soreang Kecamatan Banggae Kabupaten Majene. Skripsi.UIN Alluddin Makasar.

Fitri Retnananing Siwi, Sudarmadji, dan Suratno. 2017. Keanekaragaman dan Kepadatan Gastropoda di Hutan Mangrove Pantai Si Runtoh Taman Nasional Baluran. Jurnal Ilmu Dasar, Vol.18 No. 2, Juli 2017 : 119-124

Hartoni \& A, Agussalim. 2013. Komposisi dan Kelimpahan Moluska (Gastropoda dan Bivalvia) di Ekosistem Mangrove Muara Sungai Musi Kabupaten Banyuasin Provinsi Sumatra Selatan. Palembang

Ibrahim.2015.Metodologi Penelitian Kualitatif.Alfabeta.Bandung.

Indasari Y. 2014. Analisis yuridis hak penguasaan atas tanah timbul berdasarkan undang - undang pokok agraria dan rencana tata ruang wilayah di kecamatan teluk segara kota bengkulu. Skiripsi. Fakultas Hukum: Universitas Bengkulu.

Ira, Rahmadani, dan Nur Irawati. 2015. Keanekaragaman Dan

Kepadatan Gastropoda Di Perairan Desa Morindino Kecamatan Kambowa Kabupaten Buton Utara. Jurnal Ilmu Perikanan dan Sumber daya Perairan.Fakultas Perikanan dan Ilmu Kelautan Universitas Halu Oleo.

Isnaningsih, N, R., \& M, P, Patria. 2018. Peran Komunitas Moluska dalam Mendukung Fungsi Kawasan Mangrove di Tanjung Lesung, Pandeglang, Banten. Jurnal Biotropika. Volume 6 No.2. Universitas Indonesia.

Nurmiati, H.M Sirih,dan Parakkasi. 2016. Identifikasi Jenis-Jenis Gastropoda Dan Bivalvia Di Pantai Lowu-Lowu Kecamatan Lea-Lea Kota Baubau. Jurnal Ampibi. Vol.1. No.3 hal.( 56$60)$.

Rangan, J.K., 2010. Inventory Gastropoda in the Floor of Mangrove Forest Rap Rap Village South Minahasa Regency of North Sulawesi. Jurnal Perikanan dan Kelautan. Vol VI (1): 63-66.

Saptarini, D. I, Trisnawati.,M, A, Hadiputra. 2011. Struktur Komunitas Gastropoda (Moluska) Hutan Mangrove Sendang Biru, Malang Selatan. Surabaya, Indonesia 